\title{
Freeze Thaw Durability of Internally Cured Concrete Made Using Superabsorbent Polymers
}

\author{
Wesley A. Jones and W. Jason Weiss \\ Lyles School of Civil Engineering, Purdue University
}

\begin{abstract}
The use of superabsorbent polymers (SAPs) to produce internally cured concrete has been shown to be effective in reducing the potential for restrained shrinkage cracking of high performance concrete mixtures. However, not much is known regarding the freeze-thaw durability of concrete mixtures that incorporate SAPs for internal curing (IC). When SAP particles desorb (or partially desorb) the "water" (pore fluid) they contain for the purposes of IC, some believe that the void space created by these particles can provide enough empty voids to accommodate the additional volume caused by water expansion upon freezing. This paper investigates the freeze-thaw durability of internally cured concrete by the use of SAPs. It has been shown that internally cured concretes made using SAP demonstrate good freeze-thaw performance when the concrete is air entrained. When the SAP was used in concrete without air entrainment it did not provide sufficient freeze-thaw durability.
\end{abstract}

\section{INTRODUCTION}

Internally cured concrete has been rapidly emerging over the last decade as an effective way to improve the performance of concrete. Internal curing (IC) holds promise for producing concrete with an increased resistance to early-age cracking and enhanced durability (Bentz \& Weiss, 2011). Super absorbent polymers (SAPs) have proved to be an effective material for use in IC concrete, as they have shown potential to significantly reduce shrinkage and cracking in concrete mixtures (Jensen \& Hansen, 2001, 2002; Mechtcherine \& Reinhardt, 2012; Schlitter, Barrett, \& Weiss, 2010).

Investigation into the frost resistance of concretes with SAPs, as it relates to the air void structure, has been performed (Laustsen, Hasholt, \& Jensen, 2013; Mönning \& Lura, 2007). These studies indicate that the use of SAP has potential to reduce salt frost scaling as the voids may entrain extra air into the concrete. This was especially noticed in concrete where the SAPs are rinsed prior to mixing (Laustsen et al., 2013). Poor freeze-thaw resistance in concrete compromises the performance, and ultimately the service life, of an otherwise healthy concrete mixture. It has been shown by Jones and Weiss (2014) that if proper IC techniques are used in creating a mixture design, IC concrete using pre-wetted LWAs should have equivalent performance to a standard counterpart mixture in freezing and thawing in air-entrained concrete.

The performance of concrete in cold climates, as it relates to freeze-thaw durability, can be related to the degree of saturation (Bentz, Ehlen, Ferraris, \& Garboczi, 2001; Fagerlund, 1975, 1977; Li, Pour-Ghaz, Castro,
\& Weiss, 2011; Litvan, 1988; Scherer, 1993; Sutter, Dam, Peterson, \& Johnston, 2006). Early research established the importance of air-entrained concretes in reducing freeze-thaw damage (Cordon \& Merrill, 1963; Gonnerman, 1944; Klieger, 1952; Powers \& Willis, 1950;). As water expands upon freezing, up to $\sim 9 \%$ by volume (Powers, 1945), pressures form due to confinement by the pore walls. Osmotic pressure may also form due to partial freezing of the capillary pore solution (Powers, 1958). Additional pore volume is necessary to account for the space required during expansion, alleviating the pressure that develops. If the pores are only partially filled, the expansion from ice formation can be accommodated. If SAP particles can desorb (or partially desorb) the "water" held for purposes of IC, some believe that the void space created by the SAP particle can provide enough empty space to accommodate the additional volume caused by water expansion upon freezing (Dudziak \& Mechtcherine, 2010; Laustsen et al., 2013; Laustsen, Jensen, \& Hasholt, 2007).

This article aims to investigate IC concrete by use of SAPs, specifically as it relates to the freeze-thaw performance. The presented results were obtained from a study performed to assess the behavior of two SAP materials, received as the second phase of a round robin test (Mechtcherine et al., 2012). These mixtures will be compared with a reference mixture in which no IC methods were used, as well a mixture in which LWAs are used to supply water for IC. The main goal of testing was to expose specimens to the ASTM C666-08 Procedure A, the standardized test method for resistance of concrete to rapid freezing and thawing. In addition to freeze-thaw testing, fresh and mechanical properties of the mixtures were obtained. 
The main goals of this article are to investigate the freeze-thaw performance of IC concrete using SAPs to determine: (1) if IC concretes using SAP yield similar results to those using LWA, mainly, is the freeze-thaw performance equivalent to that of a standard mixture and (2) if the voids left by SAPs are sufficient and effective in accounting for water expansion due to freezing without the use of an air-entraining admixture.

\section{MATERIALS AND MIXTURES}

Before assessing the performance of the IC systems, it is first necessary to characterize the constituent materials. The coarse aggregate used was a Colorado $57 / 67$ crushed stone with specific gravity (SSD) and absorption (by mass) of 2.65 and $0.8 \%$, respectively. These were obtained through evaluation using ASTM C127 - 12. Gradations, per ASTM C136 - 06, are reported as percent passing for each sieve, as follows: 1" (25 mm) - 100\%, 3/4 in. (19 mm) - 88\%, $1 / 2$ in. $(12 \mathrm{~mm})-41 \%, 3 / 8$ " (10 mm) - 23\%, \#4 - 2\%, and $\# 8-0 \%$. The coarse aggregate was separated and recombined with the aforementioned gradations for each mixture. The fine aggregate used was washed concrete sand with specific gravity (SSD) and absorption (by mass) of 2.62 and $1.1 \%$, respectively. These were obtained through evaluation per ASTM C128 - 12. The fine LWA used was structural fines from Trinity Expanded Shale and Class (formerly TXI) with specific gravity (SSD) and absorption (by mass) after a $72 \pm 4 \mathrm{~h}$ soaking period of 1.85 and $18.5 \%$, respectively. These were evaluated per ASTM C1761/ C1761M - 12. No information regarding the chemical make-up may be provided about the SAPs used, at this time. Therefore, the SAPs will be referred to as "SAP 1" and "SAP 2" for this article. Both SAPs dry specific gravities were taken as 1.25 as defined in literature by Kovler \& Jensen (2005). The absorption capacities were both taken to be 20 times the dry weight, via gravimetric (by weight) methods. This will be discussed more in depth later in this article.

Type I/II ordinary Portland cement was used with a $20 \%$ replacement (by mass) of Class $\mathrm{F}$ fly ash. The chemical compositions of the cement and fly ash are presented in Table 1. The particle sizes were measured using a Coulter LS32 particle size analyser with high reproducibility $(<1 \%)$, with methanol as a dispersing admixture. The results for three trials of the particle size distributions for both the cement and the fly ash used in this study are shown in Figures 1 and 2, respectively. A full range water-reducing admixture was used for workability, as well as an air-entraining admixture, when applicable, to obtain a desired air content $(5-8 \%)$. It should be noted that different admixtures were used in creating the SAP concretes than those that were used for creating the standard and IC LWA concretes. This was done to avoid any chemical incompatibilities between the SAPs and differing admixtures. The admixtures used for the SAP concretes were provided with the dry SAP powders as part of a study. The air-entraining and water-reducing admixtures used for the standard and IC LWA mixtures are MB-AE 90 and Glenium 3030, respectively, and LP75 and Woerment FM30/ BV30, respectively, for the SAP mixtures.

Table 1. Chemical analysis of the cement and fly ash.

\begin{tabular}{lccc}
\hline Chemical & Symbol & $\begin{array}{c}\text { Type I-II } \\
\text { cement (\%) }\end{array}$ & $\begin{array}{c}\text { Class F fly } \\
\text { ash (\%) }\end{array}$ \\
\hline Silicon dioxide & $\mathrm{SiO}_{2}$ & 20.0 & 62.8 \\
Aluminum oxide & $\mathrm{Al}_{2} \mathrm{O}_{3}$ & 4.7 & 18.5 \\
Iron oxide & $\mathrm{Fe}_{2} \mathrm{O}_{3}$ & 3.2 & 4.4 \\
Calcium oxide & $\mathrm{CaO}$ & 64.0 & 5.2 \\
Magnesium oxide & $\mathrm{MgO}$ & 1.4 & 0.0 \\
Sulfur trioxide & $\mathrm{SO}_{3}$ & 3.3 & 0.6 \\
Loss of ignition & $\mathrm{LOI}$ & 2.1 & 0.7 \\
Equivalent alkalis & - & 0.6 & 0.0 \\
\hline
\end{tabular}

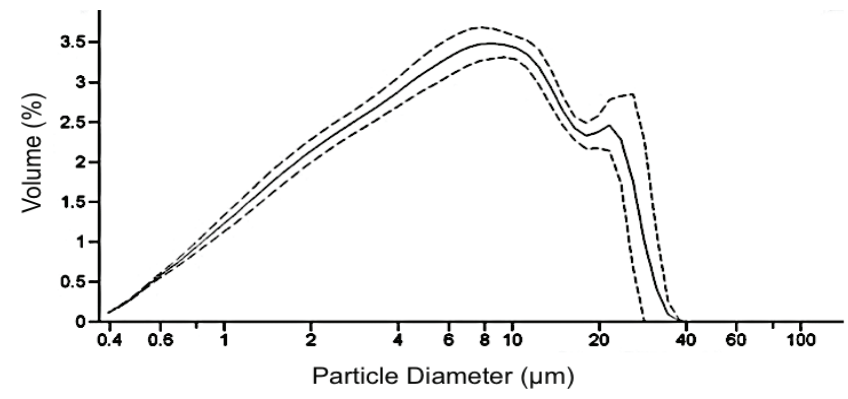

Figure 1. Differential pore size distribution, determined by laser diffraction, on three samples for the Type I-II cement.

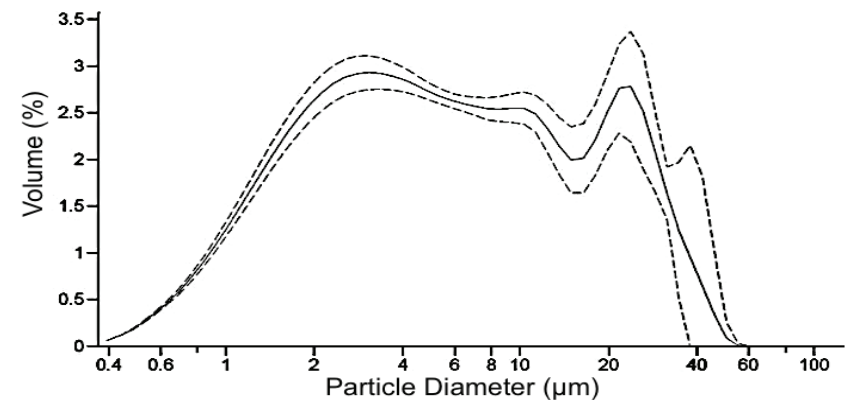

Figure 2. Differential pore size distribution, determined by laser diffraction, on three samples for the Class $\mathrm{F}$ fly ash.

The goal of IC is to provide an additional volume of curing water that is equivalent to the volume lost to chemical shrinkage. An equation for evaluating IC concrete mixtures using LWA has been developed by Bentz and Snyder (1999) and can be modified for use of SAP as shown by the following equation: 


$$
M_{\text {LWA/SAP }}=\frac{C_{f} \times C S \times \alpha_{\max }}{\phi L W A / S A P}
$$

where $M_{\text {SAP }}$ is the mass of SAP (in a dry state) required to provide water for IC, $M_{L W A}$ is the mass of the oven dry LWA, $C_{\mathrm{f}}\left(\mathrm{kg} / \mathrm{m}^{3}\right)$ required to provide water for $\mathrm{IC}$, is the cement content of the mixture, CS ( $\mathrm{ml}$ of water per $\mathrm{g}$ of cement) is the chemical shrinkage of the cement (here taken as $0.064 \mathrm{ml} / \mathrm{g}$ cement), $\alpha_{\max }$ (unitless) is the expected maximum degree of hydration (per powers model), and $\Phi_{\text {LWASAP }}$ is the absorption capacity of the LWA/ SAP.

The batch quantities for the evaluated mixtures can be found in Table 2. The aggregate quantities displayed are reported in an SSD condition, with the exception of the LWA (reported in an oven-dry condition). A total of six mixtures, a reference and five IC mixtures in which enough LWA/SAP is used to replace the water lost by chemical shrinkage, are evaluated in this article. The mixtures are described as in what follows:

1. Reference bridge deck mixture,

2. IC mixture using a replacement of fine NWA with fine LWA,

3. IC mixture using "SAP 1" with the air-entraining admixture,

4. IC mixture using "SAP 1" without the air-entraining admixture,

5. IC mixture using "SAP 2" with the air-entraining admixture,

6. IC mixture using "SAP 2" without the air-entraining admixture.

Table 2. Batch quantities for evaluated mixtures aggregate quantities are reported in and SSD condition (excluding the LWA).

\begin{tabular}{|c|c|c|c|}
\hline Material & $\begin{array}{c}\text { Reference } \\
\mathrm{lb} / \mathrm{yd}^{3}\left(\mathrm{~kg} / \mathrm{m}^{3}\right)\end{array}$ & $\begin{array}{l}\text { IC SAP } 1 / 2 \\
{\mathrm{Ib} / \mathrm{yd}^{3}\left(\mathrm{~kg} / \mathrm{m}^{3}\right)}^{2}\end{array}$ & $\begin{array}{c}\text { IC LWA } \\
\mathrm{lb} / \mathrm{yd}^{3}\left(\mathrm{~kg} / \mathrm{m}^{3}\right)\end{array}$ \\
\hline Cement & $456(270)$ & $456(270)$ & $456(270)$ \\
\hline Fly ash & $114(68)$ & $114(68)$ & $114(68)$ \\
\hline Water & $239(142)$ & $239(142)$ & $239(142)$ \\
\hline IC water* & - & $36(22)$ & $36(22)$ \\
\hline $\mathrm{FA}$ & 1493 (885) & 1412 (873) & $1211(718)$ \\
\hline LWA $^{* *}$ & - & - & $197(117)$ \\
\hline SAP & - & 1.08 & - \\
\hline CA & 1840 (1091) & 1845 (1094) & 1840 (1091) \\
\hline
\end{tabular}

Note: *IC Water indicates water available for hydration after set. ${ }^{* *}$ LWA quantities reported in oven-dry condition.

Mixing was performed in accordance with ASTM C192-07. The concrete was batched using a dual action, $3.0 \mathrm{ft}^{3}\left(0.08 \mathrm{~m}^{3}\right)$ capacity pan mixer. The materials were batched in an environment with a temperature of $73 \pm 3^{\circ} \mathrm{F}\left(23 \pm 2^{\circ} \mathrm{C}\right)$. The aggregates were prepared in the oven dry state. The fine and coarse aggregates were first combined to form a "buttered mix", adding a portion of the batch water to control dust and ensure proper water absorption for the aggregate. Next, the cement and fly ash were added to the mixer and combined with the aggregates until a uniform distribution was achieved. The remaining batch water was slowly added and the time of water to cement contact was noted. Immediately following the addition of water the SAPs/pre-wetted LWA (when applicable), water reducing admixture, and air-entraining admixture (when applicable) were slowly added directly to the concrete. From the time of water to cement contact, the concretes mixed for $3 \mathrm{~min}$, rested for $3 \mathrm{~min}$, and then mixed for an additional $2 \mathrm{~min}$.

\section{TESTING METHODOLOGIES}

\subsection{SAP absorption}

A maximum absorption capacity for the inclusions providing the curing water (in this case the SAPs, the absorption capacity of the LWA was previously reported per ASTM C1761/C1761M - 12) must be established. Although a standardized procedure for determining the absorption of SAPs does not yet exist, there are several approaches that have been discussed in literature (Elliott, 2004; Laustsen et al., 2013). For this study, a method in which a fine filter paper was used to determine the absorption for both provided SAPs. It is important to note that absorption for use in concrete should not be measured using pure water, as the absorption capacity is heavily influenced by the alkali content of the solution. To account for this, testing must be done with a pore solution similar to what will be encountered in the concrete mixtures.

Pore solution was extracted from a cement paste (with fly ash), using a mixture that was similar to the paste that is to be used in the mixture design. Solutions were extracted at ages of 30 min using a millipore pressure filtering system with nitrogen gas at pressures up to $200 \mathrm{kPa}$ (Penko, 1983). The extracted solutions were placed in a sealed container (to prevent carbonation) until the time of use. The absorption was measured by monitoring the change of mass after submersion in pore solution.

For each SAP, a $0.20 \pm 0.02 \mathrm{~g}$ sample of dry SAP powder was placed on fine filter paper and exposed to pore solution. The combination of pore solution and SAP was mixed until it was evenly dispersed within the filter. The mass of the paper and SAP was then recorded over time until an equilibrium state was reached (the moist paper mass was subtracted from the measurement). Absorption of SAPs is determined by monitoring the mass of a wet SAP 
sample in a filter as it is exposed to drying. Mass loss will become slow as it approaches a saturated state with no surface moisture (pre-wetted surface dry). This is considered the apparent absorption of the SAPs in pore solution. After submersion, the SAP is assumed to be full of pore solution and the excess water between SAP particles has been removed. Note that one must be cautious to avoid drying of both the filter paper and SAPs when performing this testing method.

The results of the absorption test for the SAPs use in this study are presented in Figure 3 . Owing to potential accuracy issues with the nature of this testing methodology, both SAPs absorptions were taken as value of $20 \times$ the dry weight, which is within $3 \%$ of the experimentally tested values. The apparent absorptions at any time, ABS $(t)$, is calculated by:

$$
\operatorname{ABS}(t)=\frac{m(t)-m_{\text {filter }}-m_{\text {powder }}}{m_{\text {powder }}}
$$

where, $m(t)$ is the mass of the total sample, including the mass of the moist filter, $m_{\text {filter, }}$ and the mass of the initially dry (or mostly dry, depending on the environment $\mathrm{RH}$ at which the powder is in equilibrium) powder sample, $m_{\text {powder }}$.

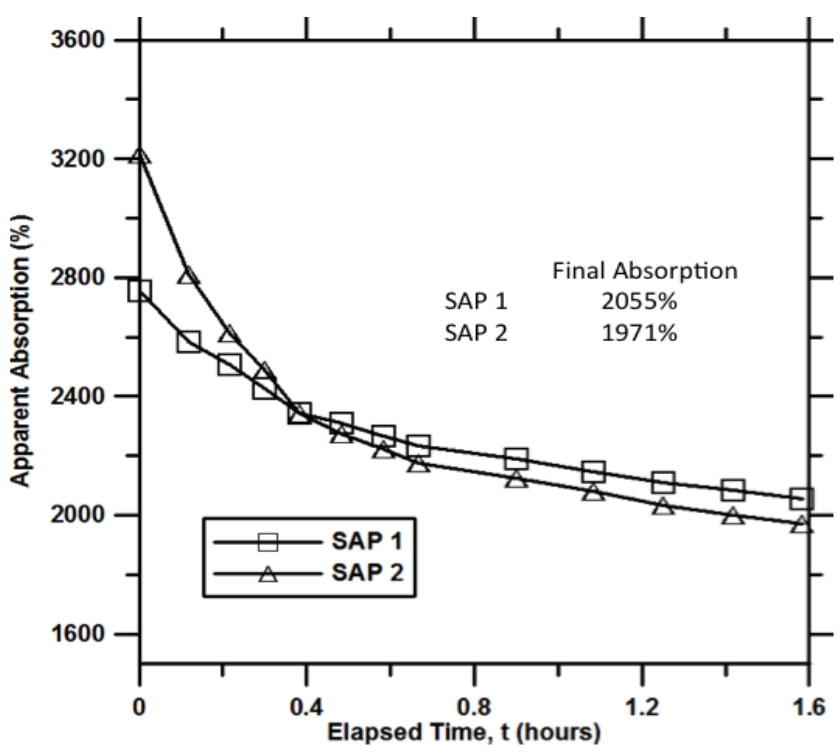

Figure 3. Apparent absorption, by mass, for the SAP1 and SAP2.

\subsection{Fresh and mechanical properties}

The hydraulic-cement concrete slump in the laboratory was determined in accordance with ASTM C143-04. After mixing the constituent materials, the mixture of interest filled a dampened standard slump cone apparatus in three lifts, being rodded 25x per lift. The cone was then removed carefully in the vertical direction in $5 \pm 2 \mathrm{~s}$, with caution against lateral and torsional motion. The vertical difference between the top of the mold and the displaced original center of the top surface of the specimen was measured and recorded to the nearest $1 / 4$ in $(6 \mathrm{~mm})$.

Since the freeze-thaw durability of internally cured mixtures is a main focus of this study, air content of the mixtures is a very important characteristic of the mixture to obtain. The air content via the pressure method was determined in accordance with ASTM C231-10. After proper mixing of constituent materials, the mixture filled the dampened, $0.25 \mathrm{ft}^{3}$ (7 I) Type $B$ measuring bowl of the air meter in two lifts, being rodded $25 \times$ per lift. After placement of each layer, the sides of the bowl were tapped $\sim 10 \times$ with a rubber mallet to close any voids left by the tamping rod and to release any large bubbles of entrapped air. The concrete was then made flush with top of the bowl using a strike off bar and the top portion of the air meter apparatus was secured. Once the top portion was secured, water was injected into one of the two petcocks, until it emerged from the other. The gauge was stabilized at the initial pressure line and the main pressure valve was released. Once the gauge hand stabilized, that value was recorded as the apparent air content of the sample tested. The total air content was then calculated by subtracting the aggregate correction factor, determined by ASTM C231-10, from the apparent air content.

The compressive strength of cylindrical concrete specimens was determined in accordance with ASTM C39-12 at an age of 28 days. Sets of three, 4 " diameter $\times 8$ " tall [100 $\mathrm{mm} \times 200 \mathrm{~mm}$ ], cylinders were cast to study the compressive strength of each mixture. A set was made for testing at ages of both 28 and 56 days. The cylinders were cast in two lifts, being vibrated and rodded $25 \times$ after each lift. After one day of curing, the cylinders were demolded, sealed, and stored in a moist chamber at a temperature of $73 \pm 3^{\circ} \mathrm{F}$ $\left(23 \pm 2^{\circ} \mathrm{C}\right)$ until testing. Three cylinders per mixture were tested to determine the average compressive strength of the mixtures. The cylinders were loaded at a rate of $35 \pm 2 \mathrm{psi} / \mathrm{s}(0.25 \pm 0.05 \mathrm{MPa} / \mathrm{s})$ in a $700 \mathrm{kip}$ (3100 kN) hydraulic compression machine, utilizing neoprene end caps.

The static modulus of elasticity (Young's modulus of elasticity) was determined using a procedure similar to that in ASTM C469-10. Sets of two, 4" diameter $\times 8$ " tall $(100 \mathrm{~mm} \times 200 \mathrm{~mm})$, cylinders were cast to study the elastic modulus. A set was made for testing at an age of 28 days. The cylinders were cast in two lifts, being vibrated and rodded $25 x$ after each lift. After one day of curing in their molds, the cylinders were demolded, sealed, and stored in a moist chamber at a temperature of $73 \pm 3^{\circ} \mathrm{F}\left(23 \pm 2^{\circ} \mathrm{C}\right)$ until tested. Upon testing, the cylinders were fitted with a compressometer that was equipped with a linear 
variable differential transformer (LVDT) displacement transducer. The cylinders were then loaded to $40 \%$ of their ultimate strength two separate times. The resulting slope of the stress-strain curve from the second loading was taken as the static modulus of elasticity. For each day of testing, two cylinders were tested for every mixture with no cylinder being tested at more than one age.

\subsection{Freeze-thaw resistance}

The rapid freezing and thawing durability of each mixture was determined in accordance with ASTM C666-08 Procedure A. Sets of three, 4-in wide $\times 3$-in tall $\times 16$-in long samples were cast for each mixture to study the resistance to rapid freezing and thawing. The specimens were cast in two lifts, being vibrated and rodded 25x after each lift, and trowel finished on the top surface. After a $24 \pm 2 \mathrm{~h}$ period the specimens were removed from the molds, bag sealed, and placed in a moist chamber at $73 \pm 3^{\circ} \mathrm{F}\left(23 \pm 2^{\circ} \mathrm{C}\right)$ for a 14-day curing period.

After the curing period, the specimens were removed from the bags and, for consistency in testing, were brought to the target internal thaw temperature, within -2 and $4^{\circ} \mathrm{F}\left(-1\right.$ and $\left.+2^{\circ} \mathrm{C}\right)$. At this point the concrete specimen masses were determined and they were tested for transverse frequency. All transverse frequency testing was performed in accordance with ASTM C215-08. After initial measurements were taken, specimens were placed in a pan with water, such that all faces were completely surrounded by not less than 1/32" [1 mm] nor more than $18^{\prime \prime}(3 \mathrm{~mm})$ of water at all times while it is being subjected to freezing and thawing cycles. The pans containing water and the concrete specimens were then placed in a chamber that underwent freeze-thaw cycling in which consist of alternately lowering the temperature of the specimens from 40 to $0^{\circ} \mathrm{F}\left(4\right.$ to $\left.-18^{\circ} \mathrm{C}\right)$ and raising it from 0 to $40^{\circ} \mathrm{F}\left(-18\right.$ to $\left.4^{\circ} \mathrm{C}\right)$ in $4 \frac{1}{2} \pm 1 / 2 \mathrm{~h}$. Specimens were removed at the desired thaw temperature and tested approximately every 36 cycles, until a total of 300 cycles, or until its relative dynamic modulus of elasticity reached $60 \%$ of the initial modulus, whichever occurred first.

\section{RESULTS AND DISCUSSION}

\subsection{Fresh and mechanical properties}

The results of the fresh properties are presented in Table 3. Enough water reducing admixture to ensure workability for purposes of laboratory placement and finishing was used for each mixture. More water reducer was required for mixtures that did not call for air-entrainer. The air-entraining admixture was added, where applicable, until an air content within a range of $5-8 \%$ was obtained. This range of air has been proven effective is freeze-thaw resilient mixtures. The amount of air-entrainer and air content was recorded and can be found in Table 3. Also reported are the plastic densities of each mixture.

Table 3. Fresh properties of evaluated mixtures.

\begin{tabular}{|c|c|c|c|c|c|}
\hline Mixture & $\begin{array}{c}\text { WRA } \\
\text { floz/cwt } \\
\text { (mL/cwt) }\end{array}$ & $\begin{array}{c}\text { AEA } \\
\text { floz/cwt } \\
\text { (mL/cwt) }\end{array}$ & $\begin{array}{l}\text { Slump } \\
\text { in }(\mathrm{mm})\end{array}$ & $\begin{array}{l}\text { Air } \\
\text { (\%) }\end{array}$ & $\begin{array}{c}\text { Density } \\
{\mathrm{lb} / \mathrm{yd}^{3}} \\
\left(\mathrm{~kg} / \mathrm{m}^{3}\right)\end{array}$ \\
\hline Ref & (430) & 0.18 & $1(20)$ & 6.6 & $3950(2343)$ \\
\hline IC LWA & $8.0(522)$ & $0.18(13)$ & $1.5(38)$ & 8 & $3900(2314)$ \\
\hline $\begin{array}{l}\text { IC SAP } 1 \\
A^{*}\end{array}$ & $9.9(644)$ & $0.46(30)$ & $2.5(64)$ & 7.2 & $3715(2204)$ \\
\hline IC SAP 1 & $12.0(778)$ & - & $1.5(38)$ & 3.8 & $3940(2338)$ \\
\hline $\begin{array}{l}\text { IC SAP } 2 \\
\mathrm{AE}^{*}\end{array}$ & $8.5(556)$ & $0.46(30)$ & $3(76)$ & 7.6 & $3740(2218)$ \\
\hline IC SAP $2^{*}$ & $13.8(899)$ & - & $4.5(114)$ & 4.2 & $3905(2317)$ \\
\hline
\end{tabular}

${ }^{*}$ Denotes mixtures in which the admixtures used differ from those used in the reference mixture.

Note: Quantities of water reducing and air-entraining admixtures are also reported.

The results of the mechanical properties are presented in Table 4. The IC SAP mixtures without an air-entraining admixture and IC LWA mixture show similar 28-day compressive strength performance. Previous research has suggested that the additional hydration in the IC samples may offset the reduction in strength due to the IC material providing water (i.e., the SAP/LWA) (Golias, Bentz, \& Weiss, 2012) mixture. Lower compressive strengths $\left(f^{\prime}{ }_{c}\right)$ were obtained for the SAP mixtures that include the airentraining admixture. This can be attributed to the additional void space created by the presence of both the SAPs and the air-entraining admixture. This creates a greater volume of voids than would otherwise not exist by just the addition of the airentraining admixture (as seen in the reference

Table 4. Mechanical properties of evaluated mixtures.

\begin{tabular}{lcccr}
\hline Mixture & $\begin{array}{c}\boldsymbol{f}_{\mathrm{c}}^{\prime}-\mathbf{2 8} \\
\text { days psi } \\
(\mathbf{M P a})\end{array}$ & $\begin{array}{c}\text { STDEV } \\
\mathbf{p s i}(\mathrm{MPa})\end{array}$ & $\begin{array}{c}\boldsymbol{E}_{\mathrm{c}}-\mathbf{2 8} \\
\text { days ksi } \\
(\mathbf{G P a})\end{array}$ & $\begin{array}{c}\text { STDEV } \\
\mathbf{k s i}(\mathrm{GPa})\end{array}$ \\
\hline Reference & $5400(37.3)$ & $140(0.97)$ & $4480(30.9)$ & $164(1.13)$ \\
IC LWA & $5800(40.0)$ & $20(0.14)$ & $4300(29.6)$ & $12(0.08)$ \\
IC SAP 1 & $4880(33.6)$ & $175(1.21)$ & $3710(25.6)$ & $230(1.58)$ \\
AE & & & & \\
IC SAP 1 & $5360(30.8)$ & $218(1.50)$ & $4250(29.3)$ & $110(0.76)$ \\
IC SAP 2 & $4460(30.8)$ & $154(1.06)$ & $4090(28.2)$ & $140(0.97)$ \\
AE & & & & \\
IC SAP 2 & $5250(36.2)$ & $36(0.25)$ & $4140(28.5)$ & $191(1.32)$ \\
\hline
\end{tabular}

Note: Quantities include the compressive strength $\left(f^{\prime}\right)$ and Young's modulus of elasticity $\left(E_{c}\right)$ at 28 days, along with the corresponding standard deviations. 
mixture), or just the addition of SAP, as is. Young's modulus of elasticity $(E)$ is slightly lower than the reference mixture for all IC mixtures, which is an expected result also attributed to the additional voids. The SAP mixtures that include air-entrainer have the lowest modulus, which further reinforces that void volume is related to modulus.

\subsection{Freeze-thaw resistance}

The results of the freeze-thaw resistant properties, per ASTM C666-08 Procedure A, are presented in this section. Figure 4 presents the average change in mass. Figure 5 presents the average change in dynamic modulus. These plots are an average of three beam specimens (geometry previously described) tested for resistance to a freeze-thaw environment. Failure of a specimen is defined by ASTM C666-08 as a loss in relative dynamic elastic modulus of $\leq 60 \%$. Relative dynamic elastic modulus is calculated as follows:

$$
P(c)=\frac{n_{1}^{2}}{n^{2}} \times 100[\%]
$$

where $P(c)$ is the relative dynamic modulus of elasticity, after $c$ cycles of freezing and thawing, $n$ is the fundamental transverse frequency at 0 cycles of freezing and thawing, and $n_{1}$ is the fundamental transverse frequency after $c$ cycles of freezing and thawing.

The final performances of each individual beam are presented in Table 5. The column labelled 'durability factor' is calculated as follows:

$$
\mathrm{DF}=\mathrm{P} * \mathrm{~N} / \mathrm{M}
$$

where $P$ is calculated per Equation (3), $N$ is the number of number of cycles at which $P$ reaches the specified minimum value for discontinuing the test or

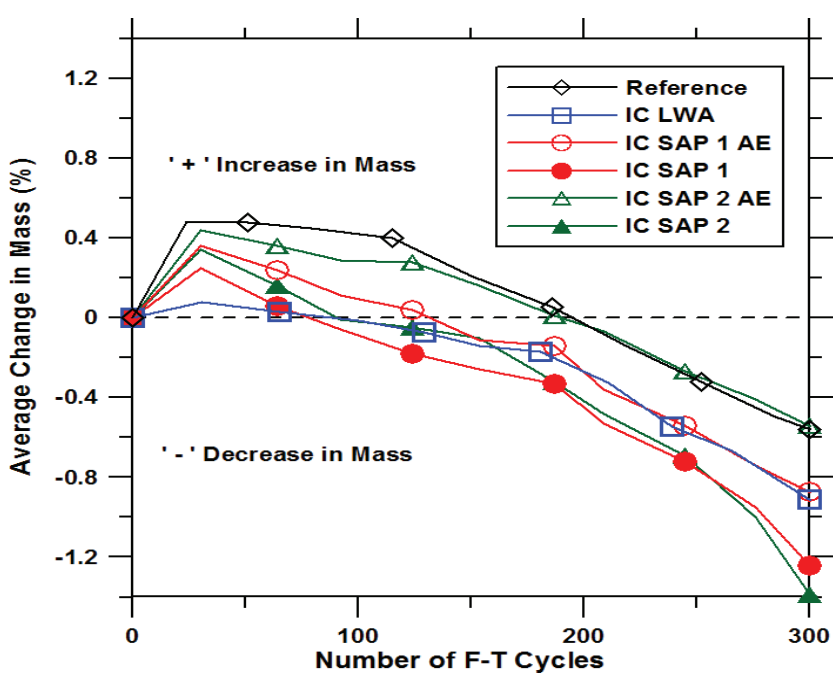

Figure 4. Plot of average mass change by ASTM C666-08 rapid freezing and thawing. the specified number of cycles at which the exposure is to be terminated, whichever is less, and $M$ is the specified number of cycles at which the exposure is to be terminated.

Based on the results of average relative dynamic modulus, shown in Figure 5, it is clear that without an air-entraining admixture, neither mixtures prepared with only SAP perform sufficiently in freezing and thawing. Both SAP 1 and SAP 2 mixtures perform satisfactorily (similar to the reference mixture) in freeze-thaw testing when an air-entraining admixture is used. This was also the case for the IC mixture using LWA; when an air entraining admixture was used the mixture performed well in freeze-thaw testing. The results presented here may suggest that voids created by SAP particles do not necessarily act as voids similar to that of an air-entraining admixture. That is to say SAP voids (at least for the SAP materials used here) may not be able to account for the additional volume formed by water expansion upon freezing. This could be due to voids created by SAPs not being as well distributed throughout the matrix as those generated by an air-entraining admixture. Another possible reason could be that SAPs are actually reabsorbing water and swelling, eliminating the void space necessary for capturing water expansion during freezing.

A mixture, similar to the reference mixture without an air-entraining admixture, should be tested in the future to determine if the SAP provides any benefit (the nonair-entrained reference mixture were to perform worse than the non-air-entrained SAP mixtures (i.e., earlier failure) than the concrete would be experiencing slight benefits from void space left by the desorbed SAP particle). However, if the non-air-entrained reference mixture were to perform similar to or better than the

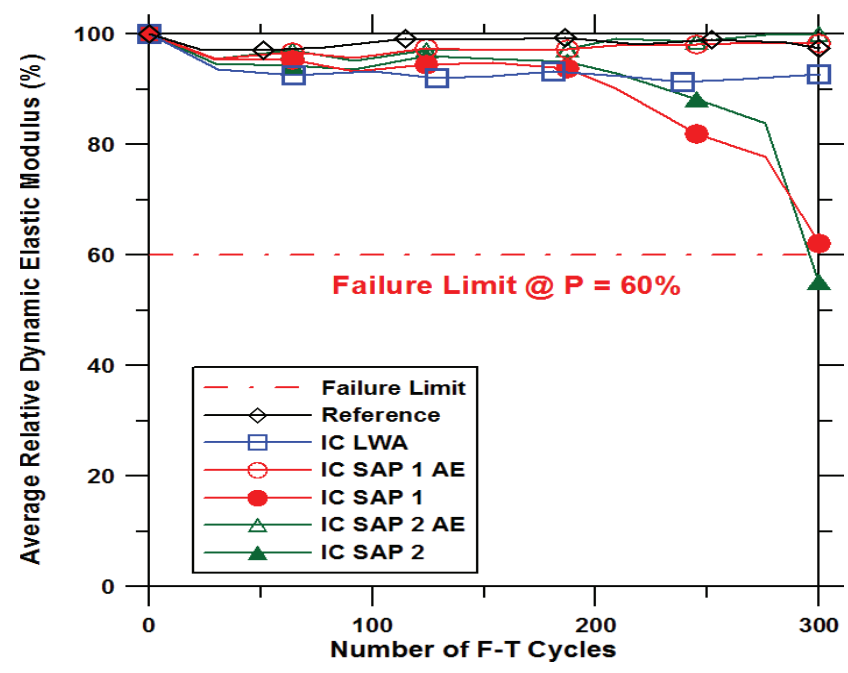

Figure 5. Plot of average relative dynamic modulus by ASTM C666-08 rapid freezing and thawing. 
Table 5. Summary of ASTM C666-08 rapid freezing and thawing data for each specimen of the mixtures evaluated.

\begin{tabular}{|c|c|c|c|c|c|c|c|}
\hline Mixture & Sample & No. cycles & Mass change (\%) & Average & Durability factor (\%) & Average DF & Pass/Fail \\
\hline \multirow[t]{3}{*}{ Reference } & 1 & 300 & $-0.60 \%$ & $-0.69 \%$ & $100 \%$ & $98 \%$ & Pass \\
\hline & 2 & 300 & $-0.76 \%$ & & $99 \%$ & & Pass \\
\hline & 3 & 300 & $-0.71 \%$ & & $96 \%$ & & Pass \\
\hline \multirow[t]{3}{*}{ IC LWA } & 1 & 300 & $-0.75 \%$ & $-0.91 \%$ & $95 \%$ & $93 \%$ & Pass \\
\hline & 2 & 300 & $-1.07 \%$ & & $91 \%$ & & Pass \\
\hline & 3 & 300 & $-0.92 \%$ & & $92 \%$ & & Pass \\
\hline \multirow[t]{3}{*}{ IC SAP $1 \mathrm{AE}$} & 1 & 300 & $-0.94 \%$ & $-0.87 \%$ & $97 \%$ & $98 \%$ & Pass \\
\hline & 2 & 300 & $-0.96 \%$ & & $99 \%$ & & Pass \\
\hline & 3 & 300 & $-0.72 \%$ & & $99 \%$ & & Pass \\
\hline \multirow[t]{3}{*}{ IC SAP 1} & 1 & 300 & $-1.17 \%$ & $-1.24 \%$ & $85 \%$ & $77 \%$ & Pass \\
\hline & 2 & 300 & $-0.91 \%$ & & $99 \%$ & & Pass \\
\hline & 3 & 245 & $-1.65 \%$ & & $47 \%$ & & Fail \\
\hline \multirow[t]{3}{*}{ IC SAP 2 AE } & 1 & 300 & $-0.56 \%$ & $-0.54 \%$ & $100 \%$ & $100 \%$ & Pass \\
\hline & 2 & 300 & $-0.37 \%$ & & $100 \%$ & & Pass \\
\hline & 3 & 300 & $-0.70 \%$ & & $100 \%$ & & Pass \\
\hline \multirow[t]{3}{*}{ IC SAP 2} & 1 & 300 & $-2.42 \%$ & $-1.39 \%$ & $29 \%$ & $55 \%$ & Fail \\
\hline & 2 & 300 & $-0.83 \%$ & & $100 \%$ & & Pass \\
\hline & 3 & 300 & $-0.94 \%$ & & $36 \%$ & & Fail \\
\hline
\end{tabular}

non-air-entrained SAP mixtures, then the conclusion would be that the SAPs have a no effect or a negative effect on freeze-thaw performance.

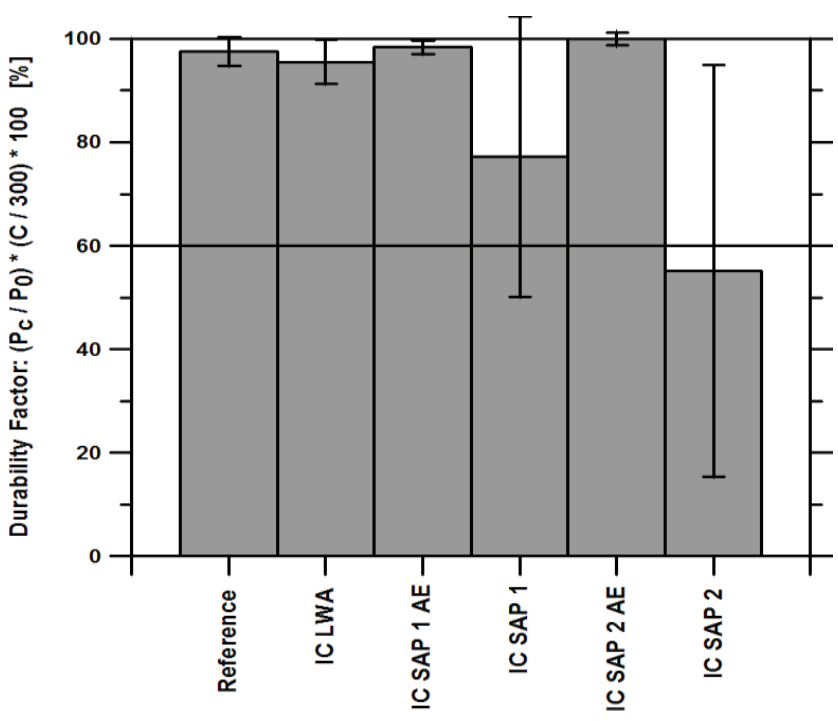

Figure 6. Summary plot of the durability factors by ASTM C66608 rapid freezing and thawing. The error bars represent standard deviations in the mixtures.

A summary of the durability factors for the mixtures is shown in Figure 6. The error bars for the mixtures are high if only one or two samples failed. It is clear when looking at the loss in average relative dynamic modulus over the duration of testing (as seen in Figure 5) for the mixtures that were not air entrained, as a whole, do not meet the ASTM C666 requirements.

\section{CONCLUSIONS}

Based on the results presented in this article, the following conclusions can be made:

1. Compressive strength $\left(f_{c}^{\prime}\right)$ is comparable to the reference mixture for mixtures the IC LWA mixture as well as the IC SAP mixtures without the addition of an air-entraining admixture. The compressive strength decreases by $\sim 15 \%$ with respect to the reference mixture (which includes air-entrainer) for mixtures that include both the addition of SAPs and air-entrainment.

2. The elastic modulus is the lowest for mixtures that include both air-entraining admixture and SAPs due to the increased void space.

3. The IC LWA and IC SAP mixtures that include an air-entraining admixture show no issues in the freezing and thawing test, per ASTM C666-08.

4. The SAP mixtures that do not include airentrainment do not pass ASTM C666-08A.

\section{ACKNOWLEDGMENTS}

A portion of study was made possible through the support provided by the Colorado Department of Transportation (CDOT) and a portion of this work was performed as part of a RILEM round robin evaluation 
from which the SAP materials were provided. This work was conducted in the Charles Pankow Concrete Materials Laboratory at Purdue University. The authors are grateful for the support that has made this laboratory and its operation possible.

\section{REFERENCES}

Bentz, D., \& Snyder, K. (1999). Protected paste volume in concrete: Extension to internal curing using saturated lightweight fine aggregate. Cement and Concrete Research, 29(11), 1863-1867.

Bentz, D., \& Weiss, W. J. (2011). Internal curing: A 2010 state of the art review. NIST IR 7765.

Bentz, D. P., Ehlen, M. A., Ferraris, C. F., \& Garboczi, E. J. (2001, September). Sorptivity-based service life predictions for concrete pavements. Proceedings of the 7th International Conference on Concrete Pavements, Orlando, FL.

Cordon, W. A., \& Merrill, D. (1963). Requirements for freezing and thawing durability for concrete. Proceedings of ASTM, 63, 1026-1036.

Dudziak, L., \& Mechtcherine, V. (2010). Enhancing early-age resistance to cracking in high-strength cement-based materials by means of internal curing using super absorbent polymers. Additions improving properties of concrete, RILEM Proceedings PRO, Bagneaux, France. Kassel, Germany; Kassel University Press, 77, 129-139.

Elliott, M. (2004). Super absorbent polymers. Product development scientist for SAP. BASF Aktiengesellschaftss, 13.

Fagerlund, G. (1975). The significance of critical degrees of saturation at freezing of porous and brittle materials. ACI Special Publication, 47.

Fagerlund, G. (1977). The critical degree of saturation method of assessing the freeze/thaw resistance of concrete. Materials and Structures, 10(4), 217-229.

Golias, M., Weiss, J., \& Bentz, D. (2013). Influence of exposure conditions on the efficacy of internal curing in concrete. Advances in Civil Engineering Materials, 2(1), 12. http://dx.doi.org/10.1520/ ACEM20120023.

Gonnerman, H. F. (1944, June). Tests of concrete containing air-entraining Portland cements or airentraining materials added to batch at mixer. $\mathrm{ACl}$ Journal Proceedings 40, 477-508.

Jensen, O., \& Hansen, P. (2001). Water-entrained cement-based materials: I. Principle and theoretical background. Cement and Concrete Research, 31(4), 647-654.

Jensen, O. M., \& Hansen, P. F. (2002). Waterentrained cement-based materials: II. Experimental observations. Cement and Concrete Research, 32(6), 973-978.
Jones, W. A., \& Weiss, W.J. (2014). Examining the freezing and thawing behavior of internally cured concrete. (Submitted).

Klieger, P. (1952). Effect of entrained air on strength and durability of concrete made with various maximum sizes of sizes of aggregate. Highway Research Board Proceedings, 31.

Kovler, K. (2012). State-of-the-art report prepared by technical committee 225-SAP, Chap. 8. In RILEM State of the Art Reports, Vol. 2. (pp. 99-114). Netherlands: Springer.

Laustsen, S., Hasholt, M. T., \& Jensen, O. M. (2013). Void structure of concrete with superabsorbent polymers and its relation to frost resistance of concrete. Materials and Structures, 2013, 1-12 http://dx.doi.org/10.1617/s11527-013-0188-0.

Laustsen, S., Jensen, O. M., \&Hasholt, M. T. (2007). Kontrolleret luftindblandingl beton (Doctoral dissertation). Technical University of Denmark Danmarks Tekniske Universitet, Department of Structural Engineering and Materials Institut for Bærende Konstruktioner og Materialer.

Li, W., Pour-Ghaz, M., Castro, J., \& Weiss, J. (2011). Water absorption and critical degree of saturation relating to freeze-thaw damage in concrete pavement joints. Journal of Materials in Civil Engineering, 24(3), 299-307.

Litvan, G. G. (1988). The mechanism of frost action in concrete: Theory and practical implications (pp. 115-134). National Research Council Canada, Institute for Research in Construction.

Mechtcherine, V., \& Reinhardt, H.-W. (2012). Application of superabsorbent polymers (SAP) in concrete construction: State of the art report prepared by Technical Committee 225-SAP. Dordrecht: Springer, RILEM.

Mönning, S., \& Lura, P. (2007). Superabsorbent polymers - an additive to increase the freeze-thaw resistance of high strength concrete. In Advances in construction materials 2007 (pp. 351-358). Berlin, Heidelberg: Springer.

Penko, M. (1983). Some early hydration processes in cement paste as monitored by liquid phase composition measurements. (Doctoral dissertation). Purdue University, West Lafayette, IN.

Powers, T. C. (1958). Structure and physical properties of hardened Portland cement paste. Journal of the American Ceramic Society, 41(1), 1-6.

Powers, T. C., \& Willis, T. F. (1950). The air requirement of frost resistant concrete. Highway Research Board Proceedings, 29.

Powers, T. C. (1945, January). A working hypothesis for further studies of frost resistance of concrete. ACl Journal Proceedings, 41(1). 
Scherer, G. W. (1993). Freezing gels. Journal of NonCrystalline Solids, 155(1), 1-25.

Schlitter, J. L., Barrett, T., \& Weiss, J. (2010).

Restrained shrinkage behavior due to combined autogenous and thermal effects in mortars containing super absorbent polymer (SAP). In O. M. Jensen, M. T. Hasholt, \& S. Laustsen (Eds.), International RILEM Conference on Use of Superabsorbent Polymers and Other New Additives in Concrete (pp. 233-242). Bagneaux, France: RILEM Publications SARL.
Sutter, L., Dam, T. V., Peterson, K. R., \& Johnston, D. P. (2006). Long-term effects of magnesium chloride and other concentrated salt solutions on pavement and structural Portland cement concrete: Phase I results. Transportation Research Record: Journal of the Transportation Research Board, 1979(1), 60-68. 